Pathophysiology of Haemostasis and Thrombosis

\title{
Leukocyte CD15 Expression and Platelet Activation in the Coronary Sinus after Coronary Intervention
}

\author{
Ursula Rauch Ursula Maria Wolff Heinz-Peter Schultheiss \\ Peter Lothar Schwimmbeck
}

Department of Cardiology and Pulmonology, University Hospital Benjamin Franklin, Free University of Berlin, Berlin, Germany

\section{Key Words \\ Leukocytes · Platelets · Adhesion proteins · Restenosis · Coronary intervention}

\begin{abstract}
Markers associated with coronary restenosis must be identified to develop therapeutic strategies for improving the clinical outcome. We studied whether adhesion proteins on leukocytes and platelets from coronary sinus blood were associated with restenosis after coronary intervention in patients with stable coronary artery disease. Adhesion proteins on platelets and leukocytes were measured by flow cytometry. Pre- and postinterventional leukocyte CD15 expression was significantly higher in patients with restenosis than in those without it. Increased leukocyte CD15 expression during the intervention may contribute to coronary restenosis. Inhibition of leukocyte adhesion may be useful for the prevention of restenosis.
\end{abstract}

Copyright $(2003$ S. Karger AG, Basel

\section{Introduction}

Coronary restenosis after percutaneous coronary intervention (PCI) is the main complication reducing the clinical success rate of PCI [1, 2]. Markers associated with coronary restenosis must be identified to develop therapeutic strategies for improving long-term outcome.

Cell adhesion proteins are involved in thrombosis and inflammation, which both play a role in the pathogenesis of atherosclerosis [3-5]. Vessel injury, platelet activation and thrombus formation as well as leukocyte adhesion and migration into the vasculature contribute to coronary restenosis. By expressing CD15, a leukocyte membranebound carbohydrate (sialyl Lewis ${ }^{\mathrm{x}}$ ), leukocytes interact with platelets via P-selectin and with endothelial cells via E-selectin [6, 7]. Inhibition of leukocyte binding to selectins by sialyl Lewis ${ }^{\mathrm{x}}$ analogues prevents intimal hyperplasia after vascular injury in animal models [8].

In humans, leukocyte-platelet interaction was increased in blood after coronary angioplasty. MAC-1 expression on circulating leukocytes was elevated in patients with chest pain after coronary angioplasty [9]. Activationdependent adhesion molecules on circulating platelets predicted acute thrombotic events after coronary balloon

Dr. Ursula Rauch

Department of Cardiology and Pulmonology

Benjamin Franklin Hospital, Free University of Berlin

Hindenburgdamm 30, DE-12200 Berlin (Germany)

Tel. +49 308445 2343, Fax +49 308445 9990, E-Mail ursula.rauch@medizin.fu-berlin.de
Fax + 41613061234 E-Mail karger@karger.ch www.karger.com

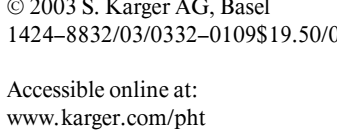


angioplasty [10]. These findings point to a possible connection between coronary restenosis and cell-associated adhesion proteins on circulating blood particles at the time of coronary intervention.

Our study examined the effect of elective coronary angioplasty on adhesion molecules expressed on circulating platelets and leukocytes obtained from the coronary sinus. The purpose of the investigation was to determine whether alterations in cell-associated adhesion proteins during angioplasty were associated with restenosis in patients with stable coronary artery disease.

\section{Material and Methods}

\section{Study Protocol}

We enrolled patients with stable coronary artery disease undergoing elective single-vessel coronary angioplasty. The study complies with the Declaration of Helsinki. All patients gave their written informed consent before enrollment. This study was approved by the Ethics Committe of the Free University of Berlin, Berlin, Germany. Patients with acute myocardial infarction, hematological disease, cancer, renal insufficiency or chronic inflammatory disease were excluded from the study. Routine laboratory blood analysis was performed on admission and included a differential blood count, platelet count, Quick test, activated partial thromboplastin time, plasma fibrinogen and serum lipid profile.

Interventional therapy was performed in the mornings. A sheath was placed into the femoral vein and femoral artery. A 5-French multipurpose catheter was placed in the right atrium into the ostium of the coronary sinus. A small amount of contrast medium was used to ensure that the catheters were located in the coronary sinus ostium. Before blood sampling, 15,000 $\mathrm{U}$ of heparin were administered intravenously. After discarding the initial $5 \mathrm{ml}$ of aspirate, blood was collected from the coronary sinus into $10-\mathrm{ml}$ plastic syringes containing heparin or platelet-stabilizing medium (heparin and citrate). The preprocedural blood sample was obtained from the coronary sinus before administration of the main bolus of contrast medium. The postprocedural blood sample was drawn from the coronary sinus after injecting contrast medium and after successful angioplasty of the left anterior descending coronary artery or the left posterior descending artery (ramus circumflexus). The coronary sinus was catheterized two times to drawn blood samples for the assessment of leukocyte and platelet adhesion proteins. To avoid an artifactual bias of the catheter line over time upon leukocyte and platelet parameters, the catheter was immediately removed from the coronary sinus after the first blood was drawn. After completing the coronary intervention, the catheter was introduced a second time into the coronary sinus for drawing blood after the intervention.

The following procedure was performed to ensure successful angioplasty: a stent was implanted, if a vessel wall dissection was visible or if an adequate lumen gain could not be achieved by balloon angioplasty alone. Severe vessel injury due to multiple balloon inflations or vessel closure before stenting could thus be avoided. Wiktor stents (Medtronic) or Sito stents (Sito-Med) were mounted onto the angioplasty balloons and deployed. Patients who were stented received ticlopidine after blood sampling and completion of the inter- vention. Thirty patients were enrolled in the study, 7 of whom were not submitted to reangiography to assess restenosis for reasons unrelated to this study. Twenty-three patients had a follow-up coronary angiography 6-8 months after the intervention to evaluate restenosis. All coronary angiograms and interventions were performed at one center (Department of Cardiology, Benjamin Franklin Hospital, Free University of Berlin). Analysis of coronary angiograms for restenosis was separately performed by an investigator blinded to the study results.

\section{Assessment of Adhesion Proteins on Platelets}

To analyze platelet adhesion proteins, blood was drawn from the coronary sinus and immediately fixed as described above [11, 12]. A single-platelet flow cytometry assay was used to measure platelet activation [10-12]. This sensitive protocol has been approved for quantifying small, but pathophysiologically important differences in platelet function [10-12]. Platelet-rich plasma was prepared from the fixed blood. The platelets were stained with monoclonal anti-CD62P (clone CLB thrombo/6), anti-thrombospondin (clone P10) and antiCD41 (clone P2) antibodies. The anti-CD41 antibody is directed against GPIIb of the GPIIb-IIIa complex. The labeled platelets were further incubated with $\mathrm{F}(\mathrm{ab})_{2}$-fluorescein isothiocyanate (FITC) fragments. Immediately thereafter, the fluorescence of 10,000 platelets was analyzed with a FACScan instrument (Becton Dickinson, San Jose, Calif., USA). The specific immunofluorescence of platelets was obtained after subtracting nonspecific immunofluorescence as determined by mouse IgG staining (fig. 1). The data were expressed as specific fluorescence in arbitrary units, which were calculated by the flow cytometry evaluation program according to the immunofluorescence staining. Validity and reliability of the system was daily monitored by the determination of immunofluorescence intensity of commercially available standard beads conjugated with FITC.

\section{Analysis of Adhesion Proteins on Leukocytes}

Blood from the coronary sinus was anticoagulated with $1: 5(\mathrm{v} / \mathrm{v})$ CPDA (sodium citrate, phosphate buffer, dextrose, adenine; Greiner, Germany). An aliquot of whole blood was diluted 1:1 (v/v) with PBS containing $1 \% \mathrm{BSA}$ and incubated with saturating concentrations of FITC-labeled monoclonal antibodies [anti-CD15 (clone 80H5) or anti-CD62L (clone Dreg 56)] for $30 \mathrm{~min}$ in the dark at room temperature. Mouse IgG conjugated to FITC was used to determine nonspecific binding. After erythrocyte lysis, leukocytes were fixed with lysing solution and fixing reagent (Coulter, Krefeld, Germany), washed in PBS and postfixed in $0.5 \%$ paraformaldehyde. Flow cytometry was immediately performed thereafter. Five thousand leukocytes were analyzed per sample. The specific CD15- or CD62L-associated FITC immunofluorescence on leukocytes was obtained after subtracting nonspecific FITC immunofluorescence. The results are expressed as a median of specific PE immunofluorescence.

\section{Statistical Analysis}

Anthropometric indices, laboratory and angiography values are given as means $\pm \mathrm{SD}$. Student's t test was used to analyze the differences between the two patient groups. Fisher's exact test was used for nominal variables (gender, medication). Since flow cytometry data were not normally distributed as assessed by the Kolmogorov-Smirnov test, values were expressed as medians and quartiles ( $75 \%$ quartile; $25 \%$ quartile). Immunofluorescence data in each group were compared before and after angioplasty using the Wilcoxon rank sum test. The Mann-Whitney U test was used to analyze differences 

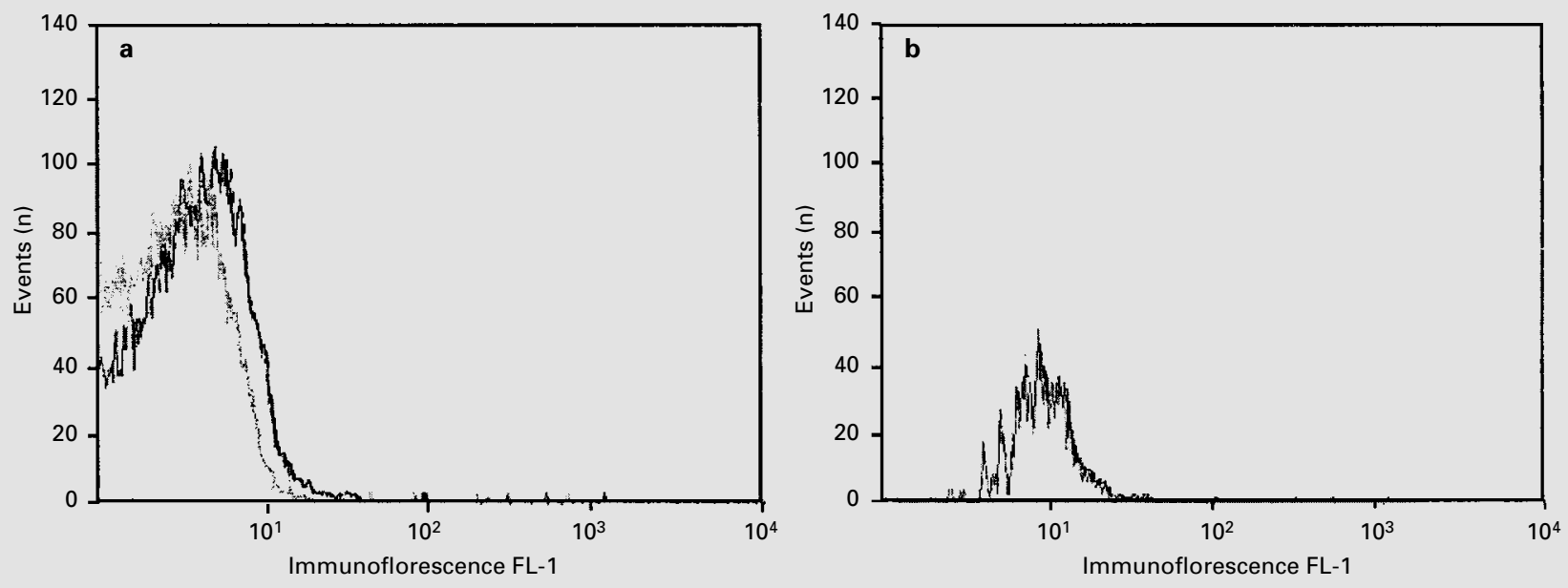

Fig. 1. Flow cytometry. a Histograms showing the platelet-unspecific immunofluorescence (FL-1) associated with mouse IgG (first histogram, grey) and the P-selectin-associated immunofluorescence on platelets (second histogram, black). b The unspecific immunofluorescence was subtracted from the P-selectin-associated immunofluorescence. The histogram seen shows the specific P-selectin immunofluorescence on platelets after subtracting the background.

between the two outcome groups. Univariate regression analysis was performed to define variables for restenosis. The two-tailed significance threshold was set at $\mathrm{p} \leq 0.05$.

\section{Results}

\section{Baseline Characteristics of the Study Groups}

Eight of 23 patients with stable coronary artery disease developed a significant restenosis within 8 months after successful dilation of the stenosed coronary. The two patient groups (with and without restenosis) showed no significant differences in anthropometric indices, laboratory data, cardiovascular risk factor profile, medication, extent of coronary artery disease, and angiographic and interventional maneuver characteristics (tables 1,2).

\section{Leukocyte Surface Markers}

With regard to clinical outcome, pre- and postinterventional leukocyte CD15 expression was significantly higher in patients with than in those without restenosis during follow-up [univariate regression analysis comparing patients with $(n=8)$ to those without restenosis $(n=15): p=$ 0.050 for preinterventional CD15 and $\mathrm{p}=0.041$ for postinterventional CD15, as shown in table 3]. CD15 expressed on leukocytes from the coronary sinus was the only parameter associated with restenosis up to 8 months after coronary intervention in patients with stable coronary artery disease. A significant reduction in CD15 expression on leukocytes isolated from the coronary sinus was only found in patients who developed a restenosis during follow-up (table 3), possibly indicating leukocyte consumption at the site of the injured vessel. No significant changes in leukocyte CD62L were found between the treatment (table 4 ) or the outcome groups (table 3 ).

\section{Adhesion Proteins on Platelets Obtained from the \\ Coronary Sinus}

Immunofluorescence showed that the activation-dependent platelet adhesion proteins P-selectin (CD62P) and TSP were significantly reduced on platelets isolated from the coronary sinus after the intervention (table 3 ). With regard to clinical outcome, a reduction in platelet activation was observed after the intervention in the patients with and without restenosis (table 3). P-selectinassociated immunofluorescence diminished by approximately $30-40 \%$ and platelet surface TSP by approximately $40-55 \%$. Patients with and without restenosis had comparable baseline and postinterventional values for the platelet surface density of P-selectin and TSP as well as for the platelet count. 
Table 1. Clinical characteristics of the study group

\begin{tabular}{|c|c|c|c|c|}
\hline & & $\begin{array}{l}\text { All patients } \\
(\mathrm{n}=23)\end{array}$ & $\begin{array}{l}\text { No restenosis } \\
(\mathrm{n}=15)\end{array}$ & $\begin{array}{l}\text { Restenosis } \\
(\mathrm{n}=8)\end{array}$ \\
\hline \multirow[t]{3}{*}{ Anthropometric indices } & Age, years & $60.8 \pm 10.6$ & $63.3 \pm 8.5$ & $54.3 \pm 12.4$ \\
\hline & Gender, female/male & $3 / 20$ & $2 / 13$ & $1 / 7$ \\
\hline & Body mass index & $26.7 \pm 3.5$ & $27.8 \pm 3.0$ & $27.8 \pm 3.6$ \\
\hline \multirow[t]{11}{*}{ Laboratory data } & Leukocytes, $\times 10^{3} / \mu 1$ & $8.5 \pm 3.1$ & $8.7 \pm 3.5$ & $8.1 \pm 1.7$ \\
\hline & Neutrophils, \% & $65.8 \pm 8.6$ & $66.4 \pm 9.1$ & $62.5 \pm 3.5$ \\
\hline & Eosinophils, \% & $2.3 \pm 1.8$ & $2.3 \pm 2.0$ & $2.0 \pm 1.0$ \\
\hline & Monocytes, \% & $8.7 \pm 3.1$ & $8.6 \pm 3.4$ & $9.0 \pm 1.0$ \\
\hline & Lymphocytes, $\%$ & $21.9 \pm 7.4$ & $21.6 \pm 8.0$ & $23.5 \pm 2.5$ \\
\hline & Platelets, $\times 10^{3} / \mu \mathrm{l}$ & $255 \pm 125$ & $262 \pm 137$ & $237 \pm 91$ \\
\hline & Total cholesterol, $\mathrm{mmol} / \mathrm{l}$ & $5.3 \pm 1.5$ & $5.3 \pm 1.3$ & $5.4 \pm 1.7$ \\
\hline & Triglycerides, mmol/1 & $2.1 \pm 1.3$ & $1.9 \pm 0.8$ & $2.6 \pm 1.8$ \\
\hline & Quick test, $\%$ & $98.1 \pm 4.8$ & $98.7 \pm 3.3$ & $96.8 \pm 7.1$ \\
\hline & APTT, s & $29.0 \pm 5.8$ & $28.3 \pm 5.4$ & $31.0 \pm 6.4$ \\
\hline & Fibrinogen, $\mathrm{g} / \mathrm{l}$ & $3.4 \pm 0.8$ & $3.3 \pm 1.0$ & $3.6 \pm 0.4$ \\
\hline \multirow{7}{*}{$\begin{array}{l}\text { Cardiovascular } \\
\text { risk factors }\end{array}$} & Current smoker & $15(65 \%)$ & $10(67 \%)$ & $5(63 \%)$ \\
\hline & Hyperlipidemia & $10(43 \%)$ & $7(47 \%)$ & $3(38 \%)$ \\
\hline & Diabetes mellitus & $10(43 \%)$ & $7(47 \%)$ & $3(38 \%)$ \\
\hline & Hypertension & $6(26 \%)$ & $5(33 \%)$ & $1(13 \%)$ \\
\hline & $\begin{array}{l}\text { History of acute coronary events } \\
\text { or previous interventions }\end{array}$ & & & \\
\hline & Coronary angioplasty & $8(35 \%)$ & $6(40 \%)$ & $2(25 \%)$ \\
\hline & Myocardial infarction & $10(43 \%)$ & $6(40 \%)$ & $4(50 \%)$ \\
\hline \multirow[t]{6}{*}{ Medication } & Aspirin & $23(100 \%)$ & $15(100 \%)$ & $8(100 \%)$ \\
\hline & Heparin & $23(100 \%)$ & $15(100 \%)$ & $8(100 \%)$ \\
\hline & Nitrates & $15(65 \%)$ & $10(67 \%)$ & $5(63 \%)$ \\
\hline & Calcium blocker & $3(13 \%)$ & $2(13 \%)$ & $1(13 \%)$ \\
\hline & Beta-blocker & $15(65 \%)$ & $10(67 \%)$ & $5(63 \%)$ \\
\hline & Digitalis & $3(13 \%)$ & $2(13 \%)$ & $1(13 \%)$ \\
\hline
\end{tabular}

Data are given as means \pm SD.

When comparing the treatment groups, the reduction in activation-dependent platelet adhesion proteins was found to be significant in patients after stenting (table 4). A trend towards a reduction in activation-dependent platelet adhesion proteins was also observed in patients treated with balloon angioplasty alone (table 4). No differences between the treatment groups were found when comparing each adhesion marker at baseline and after interventional therapy (table 4). There was no significant change in surface GPIIb expression between groups at any time (tables 3, 4).

\section{Discussion}

This study showed a link between restenosis after PCI and the presence of CD15 on leukocytes isolated from the coronary sinus. CD15 is an adhesion protein involved in leukocyte interaction with P-selectin on platelets and Eselectin on endothelial cells. The inhibition of CD15 binding to selectins by adding anti-CD15 antibodies or sialyl Lewis ${ }^{\mathrm{x}}$-containing oligosaccharides has been tested in animal models. Platelet-leukocyte adherence and cyclic flow variations were reduced in injured coronaries [13], and intimal hyperplasia was decreased [8]. The inhibition of leukocyte binding to P-selectin on platelets not only reduced leukocyte accumulation but also the deposition of fibrin within the thrombus [14]. We have recently 
Table 2. Coronary vessel stenosis, angioplasty characteristics and patient outcome

\begin{tabular}{|c|c|c|c|c|}
\hline & & $\begin{array}{l}\text { All patients } \\
(\mathrm{n}=23)\end{array}$ & $\begin{array}{l}\text { No restenosis } \\
(\mathrm{n}=15)\end{array}$ & $\begin{array}{l}\text { Restenosis } \\
(\mathrm{n}=8)\end{array}$ \\
\hline \multirow[t]{3}{*}{ Coronary vessel stenosis } & One-vessel disease & $13(57 \%)$ & $10(66 \%)$ & $3(38 \%)$ \\
\hline & Two-vessel disease & $9(39 \%)$ & $5(33 \%)$ & $4(50 \%)$ \\
\hline & Three-vessel disease & $1(4 \%)$ & $0(0 \%)$ & $1(13 \%)$ \\
\hline \multirow[t]{11}{*}{ Maneuver characteristics } & Dilations & $3.1 \pm 1.8$ & $2.9 \pm 1.5$ & $3.5 \pm 2.1$ \\
\hline & Pressure, atm & $9.0 \pm 2.0$ & $8.7 \pm 2.4$ & $9.5 \pm 1.1$ \\
\hline & Dilated vessel & & & \\
\hline & LAD & $20(87 \%)$ & $14(93 \%)$ & $6(75 \%)$ \\
\hline & $\mathrm{RCX}$ & $3(13 \%)$ & $1(7 \%)$ & $2(25 \%)$ \\
\hline & Dissections & $6(26 \%)$ & $4(27 \%)$ & $2(25 \%)$ \\
\hline & Stenting & $15(65 \%)$ & $9(60 \%)$ & $6(75 \%)$ \\
\hline & Balloon angioplasty & $8(35 \%)$ & $6(40 \%)$ & $2(25 \%)$ \\
\hline & Diameter stenosis before intervention, $\%$ & $81.3 \pm 9.1$ & $79.6 \pm 9.4$ & $84.4 \pm 7.7$ \\
\hline & Diameter stenosis after intervention, $\%$ & $16.1 \pm 10.1$ & $15.3 \pm 10.2$ & $17.5 \pm 9.7$ \\
\hline & Diameter stenosis after 6-8 months, $\%$ & $44.1 \pm 26.2$ & $27 \pm 11.7$ & $76.3 \pm 11.9$ \\
\hline \multirow[t]{2}{*}{ Clinical outcome } & Acute thrombotic event & 0 & 0 & 0 \\
\hline & Restenosis & $8(30 \%)$ & 0 & $8 *(100 \%)$ \\
\hline
\end{tabular}

$\mathrm{LAD}=$ Left anterior descending coronary artery; RCX = ramus circumflexus or left posterior descending artery. $* \mathrm{p}<0.01$.

Table 3. Clinical outcome, platelet activation and leukocyte adhesion protein expression

\begin{tabular}{|c|c|c|c|c|c|c|}
\hline \multirow[t]{2}{*}{ Intervention } & \multicolumn{2}{|c|}{ All patients $(n=23)$} & \multicolumn{2}{|c|}{ No restenosis $(n=15)$} & \multicolumn{2}{|l|}{ Restenosis $(\mathrm{n}=8)$} \\
\hline & before & after & before & after & before & after \\
\hline P-selectin & $8.1(9.5 ; 5.1)$ & $5.2^{\mathrm{a}}(6.5 ; 4.6)$ & $8.1(9.3 ; 5.1)$ & $4.9^{b}(6.2 ; 4.6)$ & $7.9(11.5 ; 6.3)$ & $5.3^{\mathrm{c}}(6.9 ; 4.6)$ \\
\hline TSP & $31(37 ; 22)$ & $17^{\mathrm{d}}(27 ; 9)$ & $30(37 ; 18)$ & $17^{\mathrm{e}}(29 ; 7)$ & $32(37 ; 28)$ & $17^{\mathrm{f}}(21 ; 13)$ \\
\hline \multirow[t]{3}{*}{ GP IIb } & $289(315 ; 254)$ & $290(337 ; 266)$ & $289(307 ; 254)$ & $284(316 ; 262)$ & $293(323 ; 262)$ & $335(376 ; 268)$ \\
\hline & & & \multicolumn{2}{|r|}{$\mathrm{p}=0.05$} & \multirow[b]{2}{*}{$\mathrm{p}=0.041$} & \\
\hline & & & & & & \\
\hline CD15 & $109(123 ; 79)$ & $107(121 ; 82)$ & $99(119 ; 76)$ & $97(114 ; 76)$ & $165(246 ; 100)$ & $155^{\mathrm{g}}(207 ; 88)$ \\
\hline L-selectin & $42(47 ; 37)$ & $41(48 ; 35)$ & $42(47 ; 37)$ & $42(46 ; 35)$ & $42(48 ; 38)$ & $41(50 ; 36)$ \\
\hline
\end{tabular}

Data are given as immunofluorescence intensity in arbitrary units (median with $75 \%$ quartile and $25 \%$ quartile in parentheses).

For platelets: $\quad$ For leukocytes:

a $p=0.001$ (before vs. after intervention).

g $p=0.01$ (before vs. after intervention), $p=0.05$ and $p=0.041$ as

$p=0.008$ (before vs. after). indicated in the regression analysis.

$\mathrm{p}=0.036$ (before vs. after).

$p=0.002$ (before vs. after).

$\mathrm{p}=0.026$ (before vs. after).

$\mathrm{p}=0.025$ (before vs. after).

Leukocytes and Platelets in Coronary

Pathophysiol Haemost Thromb 2003;33:109-115 
Table 4. Platelet and leukocyte adhesion proteins in the two treatment subgroups

\begin{tabular}{lcclcl}
\hline \multirow{2}{*}{ Intervention } & \multicolumn{2}{l}{ Balloon angioplasty $(\mathrm{n}=8)$} & & \multicolumn{2}{l}{ Stenting $(\mathrm{n}=15)$} \\
\cline { 2 - 3 } \cline { 5 - 6 } & before & after & & before & after \\
\hline P-selectin & $8.8(9.8 ; 7.0)$ & $5.3(6.1 ; 4.7)$ & & $7.6(9.2 ; 4.6)$ & $5.2^{\mathrm{a}}(6.9 ; 4.5)$ \\
TSP & $32(35 ; 22)$ & $17(28 ; 9)$ & & $30(39 ; 22)$ & $15^{\mathrm{b}}(24 ; 9)$ \\
GP IIb & $299(327 ; 278)$ & $288(331 ; 268)$ & & $271(302 ; 254)$ & $290(339 ; 266)$ \\
CD15 & $103(158 ; 78)$ & $107(142 ; 78)$ & & $109(121 ; 87)$ & $106(117 ; 87)$ \\
L-selectin & $41(45 ; 38)$ & $38(45 ; 33)$ & & $42(47 ; 37)$ & $42(48 ; 36)$ \\
\hline
\end{tabular}

Data are expressed as immunofluorescence intensity in arbitrary units (median with $75 \%$ quartile and $25 \%$ quartile in parentheses).

a $\mathrm{p}=0.01$ (before vs. after stenting).

$\mathrm{p}=0.009$ (before vs. after stenting). reported that leukocytes transfer tissue factor via CD15 binding to platelets. The transfer of tissue factor from leukocytes to platelets was significantly reduced by antiCD15 antibodies [15]. Leukocytes adherent to thrombi may not only release growth factors for smooth muscle cells but may also increase platelet thrombus growth by tissue factor deposition $[15,16]$. It is still unknown what leukocyte CD15 surface density is required for leukocyte adhesion to platelets deposited on an injured artery. It can only be speculated that patients with elevated CD15 on leukocytes may show an increased leukocyte adhesiveness to injured vasculature and platelet thrombi. Animal studies showed that the administration of CD15 analogues reduces the accumulation of leukocytes within the ischemic myocardium after reperfusion [17] and attenuates intimal hyperplasia after balloon injury [8]. These observations support the hypothesis that leukocyte deposition at the site of vascular injury contributes to the progression of atherosclerosis and the development of restenosis after coronary angioplasty. Our data agree with the findings that an increased blood level of soluble adhesion proteins like E-selectin was associated with restenosis after percutaneous transluminal angioplasty in patients with intermittent claudication [18].

A reduction in activation-dependent proteins on platelets and CD15 on leukocytes was observed during coronary angioplasty. Since leukocytes and platelets were obtained from the coronary sinus before and immediately after successful intervention, our findings may reflect a consumption of activated platelets and leukocytes during the procedure at the site of vessel injury. A loss of activated platelets during percutaneous transluminal coronary angioplasty has been reported [11]. It was suggested that circulating preactivated platelets aggregate and im- mediately respond to the performed manipulations [11]. In our study, none of the platelet adhesion proteins were found to be associated with restenosis. However, patients with restenosis show a trend towards a higher surface expression of GPIIb on platelets isolated from the coronary sinus after intervention; however, this did not reach significance due to the small number of study patients (table 4). It is possible that additional associations between adhesion molecule expression and restenosis were not detected due to the small number of study patients.

In summary, this study shows that CD15 expression on leukocytes is associated with restenosis. Further studies in humans are necessary to assess whether the inhibition of CD15-mediated interactions of leukocytes with platelets and/or endothelial cells reduces coronary restenosis after PCI. 


\section{References}

1 Detre K, Yeh W, Kelsey S, Williams D, Desvigne-Nickens $\mathrm{P}$, Holmes D Jr, Bourassa M, King S 3rd, Faxon D, Kent K: Has improvement in PTCA intervention affected long-term prognosis? The NHLBI PTCA Registry experience. Circulation 1995;91:2868-2875.

2 Erbel R, Haude M, Hopp HW, Franzen D, Rupprecht HJ, Heublein B, Fischer K, de Jaegere P, Serruys P, Rutsch W, Probst P: Coronary-artery stenting compared with balloon angioplasty for restenosis after initial balloon angioplasty. Restenosis Stent Study Group. N Engl J Med 1998;339:1672-1678.

3 Fuster V, Badimon L, Badimon JJ, Chesebro $\mathrm{JH}$ : The pathogenesis of coronary artery disease and acute coronary syndromes. N Engl J Med 1992;326:242-250.

4 Ross R: The pathogenesis of atherosclerosis: A perspective for the 1990s. Nature 1993;362: 801-809.

5 Rauch U, Chesebro J, Fuster V, Badimon JJ: Unstable angina and the role of thrombus. Acute Cor Syndr 1997;1:2-8.

6 Larsen E, Palabrica T, Sajer S, Gilbert GE, Wagner DD, Furie BC, Furie B: PADGEMdependent adhesion of platelets to monocytes and neutrophils is mediated by a lineage-specific carbohydrate, LNF III (CD15). Cell 1990; 63:467-474.
7 McEver RP, Moore KL, Cummings RD: Leukocyte trafficking mediated by selectin-carbohydrate interactions. J Biol Chem 1995;270: 11025-11028.

8 Barron MK, Lake RS, Buda AJ, Tenaglia AN: Intimal hyperplasia after balloon injury is attenuated by blocking selectins. Circulation 1997;96:3587-3592.

9 Mickelson JK, Lakkis NM, Villarreal-Levy G, Hughes BJ, Smith CW: Leukocyte activation with platelet adhesion after coronary angioplasty: A mechanism for recurrent disease? J Am Coll Cardiol 1996;28:345-353.

10 Tschoepe D, Schultheiss HP, Kolarov P, Schwippert B, Dannehl K, Nieuwenhuis HK, Kehrel B, Strauer B, Gries FA: Platelet membrane activation markers are predictive for increased risk of acute ischemic events after PTCA. Circulation 1993;88:37-42.

11 Kolarov P, Tschoepe D, Nieuwenhuis HK, Gries FA, Strauer B, Schultheiss HP: PTCA: Periprocedural platelet activation. Part II of the Düsseldorf PTCA platelet study. Eur Heart J 1996; 17:1216-1222.

12 Rauch U, Ziegler D, Piolot R, Schwippert B, Benthake H, Schultheiss HP, Tschoepe D: Platelet activation in diabetic cardiovascular autonomic neuropathy. Diabet Med 1999;16: 848-852.

13 Merhi Y, Provost P, Chauvet P, Théorêt JF, Phillips ML, Latour JG: Selectin blockade reduces neutrophil interaction with platelets at the site of deep arterial injury by angioplasty in pigs. Arterioscler Thromb Vasc Biol 1999;19: 372-377.
14 Palabrica T, Lobb R, Furie BC, Aronovitz M, Benjamin C, Hsu YM, Sajer SA, Furie B: Leukocyte accumulation promoting fibrin deposition is mediated in vivo by $\mathrm{P}$-selectin on adherent platelets. Nature 1992;359:848-851.

15 Rauch U, Bonderman D, Badimon JJ, Fallon JT, Bohrmann B, Himber J, Riederer MA, Nemerson Y: Transfer of tissue factor from leukocytes to platelets is mediated by CD15 and tissue factor. Blood 2000;96:170-175.

16 Giesen PLA, Rauch U, Bohrmann B, Kling D, Roque M, Fallon JT, Badimon JJ, Himber J, Riederer MA, Nemerson Y: Blood-borne tissue factor: Another view of thrombosis. Proc Natl Acad Sci USA 1999;96:2311-2315.

17 Lefer DJ, Flynn DM, Phillips ML, Ratcliffe M, Buda AJ: A novel sialyl Lewis ${ }^{\mathrm{x}}$ analog attenuates neutrophil accumulation and myocardial necrosis after ischemia and reperfusion. Circulation 1994;90:2390-2401.

18 Belch JJ, Shaw JW, Kirk G, McLaren M, Robb R, Maple C, Morse P: The white blood cell adhesion molecule E-selectin predicts restenosis in patients with intermittent claudication undergoing percutaneous transluminal angioplasty. Circulation 1997; 95:2027-2031. 